\title{
Courageous conversations in the Life Orientation classroom and teacher vulnerability
}

\section{Authors:}

Christa Delport de Villiers ${ }^{1}$ (D) Sarina de Jager ${ }^{1}$ (D)

\section{Affiliations:}

${ }^{1}$ Department of Humanities

Education, Faculty of

Education, University of

Pretoria, Pretoria

South Africa

\section{Corresponding author:} Christa Delport de Villiers, christa.c.devilliers@gmail.com

Dates:

Received: 31 May 2021

Accepted: 23 July 2021

Published: 04 Nov. 2021

How to cite this article: Delport de Villiers C, De Jager S. Courageous conversations in the Life Orientation classroom and teacher vulnerability. J transdiscipl res S Afr. 2021;17(1), a1097. https://doi.org/10.4102/ td.v17i1.1097

\section{Copyright:}

C 2021. The Authors. Licensee: AOSIS. This work

is licensed under the Creative Commons Attribution License.
Read online:

Rcan this OR code with your smart phone or mobile device to read online.
The Independent Education Board (IEB) introduced the need to facilitate critical conversations on controversial topics in the Life Orientation (LO) classroom at the National Conference in 2016. This shifted the focus of discussions to a facilitated critical narrative within IEB Subject Assessment Guidelines (SAGs) topics. This push followed youth activism against systemic racism at educational institutes, which initially created the perception that these conversations related to the socio-political status quo alone. However, the LO curriculum includes a range of topics that require critical narratives. Courageous conversations may trigger cognitive and emotional dissonance in both the teacher and learner. It is, therefore, crucial to interrogate the LO teachers' lived experiences in facilitating courageous conversations. This study employed individual phenomenological interviews and a focus group discussion. The participants consisted of nine LO teachers from Gauteng, Eastern Cape, Western Cape and North West province. Each individual interview focused on determining the contexts and the phenomenon of their lived experience of courageous conversations and each participant's agency in their private capacity as professional educators. The focus group discussion centred around establishing gaps in the motivation, training and skill development of LO teachers to facilitate these conversations. The findings indicate that the courage required of teachers to challenge and be challenged, albeit in a safe environment, results in teacher vulnerability.

Keywords: courageous conversations; vulnerability; Life Orientation; critical agency, dissonance triggers, autonomy, lived experience, negotiated space.

\section{Introduction}

Life Orientation (LO) teachers are encouraged to provide their learners with exposure to multiple perspectives and academically sound knowledge. The content must allow them to critically analyse opinions, views and beliefs that manifest in democracy, human rights, gender and sexuality, mental health and identity development. ${ }^{1,2}$ These courageous conversations occur in LO classrooms where teachers need to develop an agency to negotiate the trust relationship with their learners that make the possible vulnerability of the teacher meaningful, despite the professional dissonance that the conflicting values between school and subject may trigger. ${ }^{3,4,5}$ During this study, the LO teacher's lived experience of courageous conversations in the LO classroom was explored. Both teacher and learner share this space within which the courageous conversation occurs with openness, honesty, trust and safety. ${ }^{6,7,8}$ This integrated sharing of learning and teaching could enrich identity development and the meaning attached to the courageous conversation as a learning process. The facilitation of courageous conversations depends on the teacher's ability to reflect and grow their personal beliefs, develop high professional courage, re-frame their critical agency and remain motivated to facilitate these conversations., ${ }^{9,10,11}$ It is crucial that the teachers' model of facilitation, self-regulation and growth determine the trust relationship between the teacher and learners. ${ }^{5,12,13}$

\section{Background to the study}

The informal directive from the Independent Education Board (IEB) in 2016 to facilitate courageous conversations as a LO teaching practice shifted the focus from an informal approach to critically analysing selected content, seen as potentially controversial, to utilise in an open formal conversation. This shift in teaching methodology presented a challenge to LO teachers. ${ }^{14}$ The teacher's level of professional skill and experience directly correlated with their confidence and motivation to select specific content that learners may experience as sensitive, to enhance the LO curriculum. ${ }^{15}$ Perceptions held about LO since its implementation as a compulsory subject have been and continue to be tenuous. ${ }^{16}$ The support for both LO as a subject and the LO 
teacher as an academic is often limited, resulting in greater rates of teacher turnover and a compounded lack of specialised LO teachers to meet the increased demand for a higher academic standard in this subject. ${ }^{17}$ In independent schools, there is more flexibility in applying subject curricula and structured timetables. ${ }^{18}$ In LO, the battle for sufficient time allocation continues. Consequently, in smaller schools, it is likely that the entire LO department will consist of only one teacher. ${ }^{19}$ Few LO teachers can teach their subject with complete autonomy, managerial support and with respect for the value of the subject they teach and for the challenges integral to the context and nature of the LO curriculum. ${ }^{20}$ The LO teacher has a significant need for professional courage when negotiating a safe space within which courageous conversations can be facilitated with their learners truthfully, openly, safely and honestly. ${ }^{21,22}$

\section{Aim and objectives}

The study's objective is to describe how LO teachers attach meaning to teaching topics they deem sensitive, and that need to be facilitated through courageous conversations to develop critical citizenship skills. ${ }^{17,23}$ Empathy and knowledge of one's learners are vital in enabling the teacher to create an environment where these open and truthful conversations can occur and foster trust and understanding. ${ }^{24,25}$ Furthermore, the study aimed to provide insight into the existing gaps in skills development, dissonance and motivation to facilitate the conversations that require professional courage. ${ }^{26,27}$ Identifying factors contributing to the LO teachers' sense of vulnerability is vital in understanding their choices of content, the boundaries of the school culture, the availability of a support system and the level of respect and trust that exist in the space where they need to implement these difficult conversations. ${ }^{28}$

\section{Research methodology}

This qualitative study implemented a phenomenological approach to focus on the lived experiences of LO teachers. Phenomenology was a suitable approach to understand and describe the complexities of the teachers' lived experiences, anecdotes thereof, and emotions experienced during courageous conversations. The data obtained from the indepth phenomenological interviews of the participants' lived experiences and the focus group discussion enabled the development of 'seamless perspectives' to describe these different experiential realities authentically. ${ }^{29,30}$ In-depth phenomenological interviews with nine teachers and a focus group discussion were utilised.

Bevan describes the phenomenological approach as a threephase process: contextualisation of the participant's lifeworld, apprehension of the phenomena or lived experience of the participant and clarifying the phenomenon to focus on specific aspects of the lived experience. ${ }^{31}$ These three phases provided a practical structure and confirmation that ensured that the phenomena were fully clarified from the data collection process.

\section{Data collection}

Nine teachers were selected based on their experience as subject heads of LO, as cluster leaders or regional moderators or both. Furthermore, the participants have experience as either NSC Portfolio moderators or national Common Assessment Task (CAT) examiners. The implementation of online teaching in March 2020 allowed for the inclusion of participants from Cape Town, Eastern Cape, North West province and Gauteng. This inclusion ensured a more diverse group of participants, who included teachers from religious schools, a dual-medium school, transdisciplinary teachers, teachers who are mainly sports specialists and teachers who are dedicated LO specialists.

The individual interviews consisted of a set of leading semistructured questions used to design a critical questioning approach. The main question posed to participants were What are your experiences of courageous conversations in the LO classroom? The interpretivist researcher role allowed the questions to evolve according to participant responses. ${ }^{32}$ The structure consisted of three phases: Phase 1-contextualisation, Phase 2 - apprehension of the phenomenon and Phase 3 interpretive and imaginative questions. ${ }^{31,33}$ The interaction included opportunities to self-regulate any dissonance that resulted from the critical conversations. ${ }^{34,35,36}$ The focus group discussion consisted of a further set of semi-structured conversations to authenticate responses during the individual interviews or address gaps in the data gathered. ${ }^{33,37}$

The transcribed interviews and discussions were analysed according to Tesch's Eight Step Coding process. ${ }^{38}$ Each interview was read to identify key phrases to structure the data; commonalities between these key phrases were identified to create main thematic headings; the supporting themes were resorted under each main thematic heading. The third tier of thematic subheadings that enable the interpretation of the data was identified and assimilated to structure a rich, in-depth and detailed analysis of the findings. ${ }^{38}$

Ethical clearance was obtained from the University of Pretoria's Research Ethics Committee. Thereafter, participants who met the criteria were approached and presented with informed consent. Participants were notified that they could withdraw at any stage of the study.

\section{Findings}

The three main emerging themes will form the focus of this article. The participants indicated the following themes as consistent contributing factors to their motivation to develop dynamic content for courageous conversations: (1) vulnerability, (2) teacher's experience of a lack of autonomy and (3) fostering mutual respect in the LO space.

The nine schools represented by the participants were found to have a demographic that ranged from $90 \%$ black learners, indigenous learners and learners of colour (BIPOC) learners to $90 \%$ white learners. The approximate average learner 
demographic was $45 \%$ - $65 \%$ white learners approximately $25 \%$ - 35\% black learners (here referring to African individuals), $10 \%$ bi-racial learners approximately 5\% coloured learners and 10\% - 15\% Indian learners. The majority of schools are situated in urban middle to upper middle-class areas. One of the schools were situated in a rural farming area and therefore found access to resources, which were easily accessible by urban schools, a challenge. The teaching environments consisted of historical schools, religious schools serving a specific denomination, religious schools that do not serve a particular denomination and a very liberal school.

\section{Vulnerability}

Participant C mentioned that:

'I think I do this [refers to strategising according to potential triggers] all the time; I literally think I have a back-up plan for every statement I make in class. [All round laughter] I feel like it is a continual problem, I always ... every time I say something I review it, and I'm like what happened, if this child leaves the room and say that this happened, will there be kids that will back me up.' (Participant C, LO teacher)

Further feelings of vulnerability are expressed by Participant I when she says:

'... in LO you are talking about feelings, you are talking about perceptions and there is no guidebook to that and that is why you are so nervous all the time because what you are doing is you are negotiating the space, you don't know how learners are going to react to things [specific current content to augment the curriculum] because you cannot hide behind this is fact ...' (Participant I, LO teacher)

\section{This participant further added that:}

'... what you [the LO teacher] are doing is getting learners to engage with opinions openly and honestly having those courageous discussions, but at the same time it is unchartered territory and that is scary and you never know what side you are going to get, and even in a school like mine [liberal, upper-middle-class] that tries to bring this critical learning attitude across I still feel that fear in the classroom.' (Participant I, LO teacher)

Participant B described the following:

'I am constantly grappling ... and I think that is why I started the year off so badly - I never felt I was on top of things despite how well I was prepared.' (Participant B, LO teacher)

\section{Life Orientation teachers experience a lack of autonomy}

Participant $C$ described that:

‘We are also almost seen as people who may have instigated problems rather than actually seeing us as doing a good job by actively discussing these problematic issues with the learners.' (Participant C, LO teacher)

Participant E illustrated the impact of current unease:

'... for the first time in all the years that I've been here, management wanted my LO books, for each and every single grade, he went through them and then called me in for a meeting and now I've got purple dog tags that he put into topics that I have to chat to him about first, before I'm allowed to tackle it in class.' (Participant E, LO teacher)

Participant A stated that the demands made of LO teachers are often unrealistic and stand in stark contrast to the dismissal of LO as having poor educational value and of LO as a non-academic subject.

Academically the initial description of LO as a compulsory subject was as experiential, and the allocation of only 10 credits led to the assumption that the subject would have a lower academic standard. Therefore, the expectation was for LO to account for exponentially greater numbers of subject distinctions. This, despite the requirement, stipulated in the LO Subject Assessment Guidelines (SAGs) for LO to be taught and assessed using the same Bloom's taxonomy levels as all other subjects. ${ }^{20}$ Participant $C$ illustrated the lack of managerial support as:

'You know I am never called into a meeting at any other time, but I am called into meetings, not to hear how I am or how LO is going - it is just "Why do you not have more distinctions?"' (Participant C, LO teacher)

It was clear from five of the respondents that praise or acknowledgement for LO and the work performed, skills needed and the constant need to be able to respond with sound knowledge to the learners' questions about an increasingly complex world, an increasingly fluid and sensitised society, and the toxic dynamic between society and environment. Participant I stated that:

'The need to interact critically and challenge the power relationships between racial groups, gender identities, sexual orientations, the decline in mental health, the fragility of environmental resources has not decreased, it has increased. So much needs to be performed constantly by an LO teacher to stay current, source content, design new lessons, and have factual substantiation for everything we take into that LO Space.' (Participant I, LO teacher)

'The need to prove oneself as an LO teacher is far greater on young inexperienced teachers, who do not have the skills or knowledge to manage expectations or to set boundaries and make enough time to self-reflect and self-regulate. This further increases the high turnover rate of teachers that weakens the subject.' (Participant B, LO teacher)

However, participants seem to feel that a loss of autonomy can be minimised by supportive mentorship:

'With maturity and experience, it is far easier to negotiate boundaries and set limits according to your level of expertise.' (Participant E, LO teacher)

Becoming assertive and setting clear boundaries reflect a conscious choice to adapt to becoming a strategist and facilitator as their set teacher behaviour and becomes the coping mindset needed to facilitate courageous conversation. However, as Participant $C$ reflected:

'... preparing for every possible question and being prepared with a coping strategy for every possible contentious response or 
risk of confrontation becomes mentally exhausting.' (Participant C, LO teacher)

The importance of overcoming the lack of time to reflect and self-regulate is described by Participant $\mathrm{D}$ as follows:

'... 2020 [despite the Covid protocols and online teaching] just that time helped me to gain a new perspective and to really look at myself, like look at what am I really here for as a LO teacher? What should my focus be?' (Participant D, LO teacher)

The professional courage required from the LO teachers increases their vulnerability and professional risks, but without support, it results in self-isolation triggered by their fear of failure. Participants G shared that:

'... one parent just ripped everything [LO content covered in the classroom] to shreds for about a year - it affected me emotionally, and basically I didn't teach those aspects for a while. I basically said to the school. The school needs to actually say, don't teach that, if that's what they want. If they say don't teach it, then I won't teach it.' (Participant G, LO teacher)

\section{Fostering mutual respect in the Life Orientation space}

Despite the challenges faced by LO teachers, there are many aspects that provide motivation to the teachers. Participant $\mathrm{H}$ stated that:

'You have to love this subject; the interaction with the learners, mentoring them until they have those "Aha-moments." Providing well-placed scaffolding until they are ready to embrace the challenge and extend themselves, all while learning to listen and learn with others equally.' (Participant H, LO teacher)

Participant G stated that experienced teachers who are aware of and can sufficiently manage their workload have longevity, emotional intelligence, aptitude and a thirst for new knowledge. These teachers also have internal motivation and are energised by challenging and rigorous debate - they find LO a beautiful subject.

Participant $G$ described the impact of mutual respect as follows:

'... when it comes to learners and in the classroom, then I'm only uplifted by what happens. I've never walked away from a lesson with learners and felt "That was dreadful" or felt upset or whatever - never!' (Participant G, LO teacher)

Participant D described the need for mutual respect as follows:

'... part of our role as LO teachers is to challenge learners on statements that are made, and in that challenging ... there has got to be an element of trust in a teacher, and respect for a teacher's capabilities.' (Participant D, LO teacher)

Participant A mentioned that:

'... it is paramount that LO teachers focus on getting to know their learners, gauge their maturity levels and their readiness before they move on to the self-analysis of their own beliefs and opinions during Grade 11 and Grade 12.' (Participant A, LO teacher)
Participant B added to Participant A's comment that:

'Learners have to be provided with the cognitive scaffolding to identify their triggers, understand them and practice how to reflect on and accommodate cognitive and emotional dissonance so that they may be able to cope with a peer or teacher challenging their opinions.' (Participant B, LO teacher)

The bond that is created between teacher and learner and learners with their peers in a relationship characterised by mutual respect is illustrated by Participant G:

'I've got one youngster in matric, who as he has realised that he actually has a voice, he is just the most amazing youngster, and he has this wealth of knowledge ... because he's the one, at the end of our meeting the other day, who said "I just want to say, if any of you are feeling uncomfortable after this, that's OK, you're on the road to recovery." How sweet is that - "you're on the road to recovery."' (Participant G, LO teacher)

\section{Discussion of findings}

The participants experienced vulnerability, to be attributable to a lack of support from school management and colleagues, specifically regarding broad, often unrealistic, expectations of expertise regarding social issues that are considered the purview of LO. ${ }^{39}$ This teacher's vulnerability is further compounded by negative perceptions of LO's value, a general lack of understanding of the context and content of LO and socio-historical trauma experienced by BIPOC teachers, learners and parents. ${ }^{15,40}$ The participants expressed that they had to learn to be assertive in dealing with unrealistic expectations and the lack of recognition in developing an improved perception of the academic value of their subject. ${ }^{7}$ They also had to develop coping skills to overcome the challenges that deplete their professional motivation and result in the lack of teacher longevity. ${ }^{41}$ The impact of maintaining this learned teacher behaviour made it vital to utilise self-reflection as restorative self-care and to rely on internal motivation independent of an external support system. ${ }^{12}$

It is not merely the workload but the mental drain of being fearful of reprisals. ${ }^{24}$ Teachers must constantly be cognisant of parent's and management's possible reaction to the content analyses of belief systems and worldviews that are common during courageous conversations. A backlash from learners, parents and management because of the content analyses of belief systems and world views of which they must be cognisant. ${ }^{42}$ It is impossible to remove racial identity and perspectives from the curriculum topics or content of LO as a subject area because culture and ethnicity are a big part of how meaning is added to the lived experiences and how the LO teacher interacts with their learners. ${ }^{10}$ Therefore, it is not unusual that the conversations at home that become evident in the classroom also indicate that the classroom conversations feature around the dinner table at home. ${ }^{43}$ The importance of socio-historical perceptions is still inherent and needs to be acknowledged and resolved. ${ }^{10}$ 
The skills to negotiate an LO space in which there is trust, respect, accommodation and openness, need to be honed constantly. ${ }^{9}$ This negotiation starts each year afresh, with each new class. It remains very stressful and LO teachers remain nervous in this space. It is not possible to pre-empt all responses, you are actively negotiating that trust relationship and safe space with each courageous conversation. The lack of understanding, especially from management, the courage and motivation needed to navigate the specific content and context of LO and courageous conversations is an increasing drain on the LO teacher's self-motivation.

Most participants indicated that they find it easier to foster openness with their learners by using themselves and their combined lived experiences as subject matter in general LO lessons and courageous conversations. ${ }^{4}$ Taking this risk makes the trust relationship between teacher and learner integral to the honesty and respect negotiated in this safe LO space. ${ }^{35}$ The common denominator in the various participants' individual critical agencies for their teaching praxis is that with LO, through promoting personal growth and development, the concept of an evolving worldview is to afford young adults with an agency that is crucial to the world beyond school. ${ }^{21}$

Identifying the factors that are contributing to the LO teachers' sense of vulnerability is vital in understanding their choices of content, the boundaries of the school culture they need to navigate, the availability of a support system (internal or external) and the level of respect and trust that exist in the space where they need to implement these difficult conversations. ${ }^{17,28}$

\section{Recommendations}

There is a clear need to create training opportunities and hands-on workshops for LO teachers, especially regarding the setting of boundaries and negotiation of a safe space for courageous conversations. Their existing skills need to be updated to be able to open up controversial topics and discussions. Clear efforts should be made to create a better understanding and insight into the context and content of LO. Management structures especially should be encouraged to be more supportive of the value added to the affective and psychological becoming of the learner in the LO classroom.

\section{Conclusion}

Life Orientation teachers had to adjust their teaching practice to accommodate the informal directive from the IEB to implement conversations on controversial issues in the classroom. ${ }^{14}$ However, the LO curriculum additionally encompasses many topics, such as democracy, race, gender, sexuality, belief systems, political policies and human rights that do not have set content to provide the LO teacher with the flexibility to keep the content current and valid to their learners. Attempting to plan for all possible questions or perspectives, that may manifest in their classroom during a critical discussion compounds the teacher's constant sense of being vulnerable. It is important to identify accessible support systems to provide LO teachers with the skills to self-regulate, practice self-care and restore their waning motivation and positive decision making. It is only when the teacher can balance effective and meaningful experiences, without fearing the challenges and discomfort, that the lived experience of courageous conversation can continue and the value and academic impact of the LO subject and teacher can fully be achieved.

\section{Acknowledgements Competing interests}

The authors declare that no competing interest exists.

\section{Authors' contributions}

C.D.d.V. conceptualised and executed the study as this article is based on her Masters dissertation. S.d.J. supervised the process, edited the article and added to the writing.

\section{Funding information}

This research received no specific grant from any funding agency in the public, commercial or not-for-profit sectors.

Other than the change to electronic meetings platforms used, permission for which was granted by the Faculty of Education, all guidelines and criteria set out by the Ethics Committee were adhered to with great care. All data is stored in accordance with the guidelines as provided by the Ethics committee of the Faculty of Education, University of Pretoria: HU 190201.

\section{Data availability}

Permission to access data can be requested from the supervisor of the study, Dr Sarina de Jager (sarina.dejager@ up.ac.za), upon reasonable request. The study was still in progress at the time of this article's publication.

\section{Disclaimer}

The views expressed in this article are the researcher's and not the official position of the University of Pretoria.

\section{References}

1. Independent Examination Board (IEB). Life orientation subject assessment guidelines. Johannesburg: IEB, 2018; p. 1-18.

2. Independent Examination Board (IEB). Independent Examination Board regional user group conference. Johannesburg: Independent Examination Board (IEB); 2019.

3. Bongwe SI. 100 lessons in DIVERSITY: Learning about yourself and others. 1st ed. Johannesburg: The Diversity Centre; 2010.

4. Francis $D$, Le Roux $A$. Teaching for social justice education: the intersection between identity, critical agency, and social justice education. S Afr J Educ. 2007;31(3):299-311. https://doi.org/10.15700/saje.v31n3a533

5. Ashton R. Professional courage: What does it mean for practitioner psychologists? Educ Res Pract. 2017;3(1):2-14.

6. Singleton GE. Courageous conversation about race. 2 nd ed. Thousand Oaks, CA CORWIN, a Sage Company; 2014

7. Ally M. White South African identity and an ethic of reconciliation: Racism, guilt and a sense of shame. Politeia. 2006;25(1):30-40.

8. Huynh A. Courageous conversations about race: Exploring counter-narratives on black heritage day. Sch Stud Educ. 2013;10(2):274-280. https://doi.org/10.1086/673334 
9. Guerra PL, Nelson SW, Jacobs J, Yamamura E. Developing educational leaders for social justice: Programmatic elements that work or need improvement. Educ Res Perspect. 2013;40(1):124-149.

10. Gorski PC. Cognitive dissonance as a strategy in social justice teaching. Multicult Educ. 2009;(Fall):54-58.

11. Ramphele M. Conversations with my sons and daughters. 1st ed. Johannesburg.: Penguin Books, 2012; p. 147-203.

12. D’Aunno L, Heinz $M$, Kramer $E$, Lint $S$. Continuing courageous conversations toolkit. Des Moines, WA: The National Resource Center for Family Centered Practice; 2017.

13. Fowler S. Breaking the silence: A qualitative critical autoethnography of a principal's lived experience with having courageous conversations. Kansas City, MO: University of Missouri-Kansas City; 2016.

14. Mowatt R. Teaching controversial issues in the classroom. Presentation, National User Group Conference: Life Orientation. National User Group Conference 2016. Johannesburg: Independent Examination Board (IEB); 2016.

15. Brown J. Attitudes and experiences of teachers and students towards life orientation a case study of a state-funded School in Eldorado Park, South Johannesbur Supervisor: Prof. David Dickinson. Johannesburg: University of Witwatersrand; 2013.

16. Jansen J. The lost scholarship of changing curricula. S Afr J Sci. 2017;113(5/6):7-9. https://doi.org/10.17159/sajs.2017/a0209

17. Ferguson R, Jain M. Op-Ed: Active citizenship requires active learning - The case for valuing life orientation. Daily Maverick [serial online]. 2015 [cited 2018 Nov 25]; p. 1-6. Available from: https://www.dailymaverick.co.za/article/2015-01-22 op-ed-active-citizenship-requires-active-learning-the-case-for-valuing-lifeop-ed-active-ci

18. ISASA, Department of Basic Education. Rights and responsibilities of independent schools. Johannesburg: ISASA, 2008; p. 1-8.

19. South Africa. National curriculum and assessment policy statement grades 10-12 Life orientation. Department of Basic Education, Republic of South Africa; 2011. South Africa: Pretoria.

20. IEB. Life orientation subject assessment guidelines: Grade 10-12. 2019. South Africa: Independent education Board.

21. Oyserman D. The essentialized self: Implications for motivation and self-regulation J Consum Psychol. 2019;29(2):336-343. https://doi.org/10.1002/jcpy.1093

22. Walker M, Iverson E. Identity Development and Political Self-Regulation in Emerging Adult Political Attitudes and Behavior. Emerg Adulthood. 2016;4(3) 153-160. https://doi.org/10.1177/2167696815585052

23. Badat S, Sayed Y. Post-1994 South African Education. Ann Am Acad Pol Soc Sci. 2014;652(1):127-148. https://doi.org/10.1177/0002716213511188

24. Vandeyar S, Swart R. Educational change: A case for a 'pedagogy of compassion'. Educ Chang. 2016;20(3):141-159. https://doi.org/10.17159/1947-9417/2016/1362

25. Amin N, Vithal R. Teacher knowing or not knowing about students. South African J Educ 2015;35(3):1-9. https://doi.org/10.15700/saje.v35n3a1078

26. Baumeister RF, Vohs KD. Self-regulation, ego depletion, and motivation. Soc Personal Psychol Compass. 2007;1(1):1-14. https://doi.org/10.1111/j.1751 9004.2007.00001.x
27. Maruven M. Ego depletion. In: Encyclopedia of Social Psychology. Sage, 2011; p. 1-2. Thousand Oaks, CA: Sage Publications.

28. Roddick P. Dangerous classrooms. Johannesburg: IEB; 2017.

29. Thanh NC, Thi T, Thanh L. The interconnection between interpretivist paradigm and qualitative methods in education. Am J Educ Sci [serial online]. 2015 [Cited 13 March 2019];1(2):24-7.

30. Taylor PC, Medina MND. Educational research paradigms: from positivism to multiparadigmatic. J Meaning-Centered Educ. 2013;1(2007):1-16

31. Bevan MT. A method of phenomenological interviewing. Qual Health Res. 2014;24(1):136-144. https://doi.org/10.1177/1049732313519710

32. Lüddecke F. Philosophically rooted educational authenticity as a normative ideal for education: Is the International Baccalaureate's Primary Years Programme an example of an authentic curriculum? Educ Philos Theory. 2016;48(5):509-524. https://doi.org/10.1080/00131857.2015.1041012

33. Tuli F. The basis of distinction between qualitative and quantitative research in social science: Reflection on ontological, epistemological and methodological perspectives. Ethiop J Educ Sci. 2011;6(1):97-108. https://doi.org/10.4314/ejesc. v6i1.65384

34. Zacher H, Schmitt A, Jimmieson NL, Rudolph CW. Dynamic effects of personal initiative on engagement and exhaustion: The role of mood, autonomy, and support. J Organ Behav [Internet]. 2019;40(1):38-58. https://doi.org/10.1002/ job.2277

35. Janz J Timmers M. Emotional dissonance: When the experience of an emotion jeopardises an individual's identity. Theory Psychol. 2002;12(1):79-95. https:// doi.org/10.1177/0959354302121005

36. Holmes AG. Researcher positionality - A consideration of its influence and place in research. Researchgate, 2014; p. 28.

37. Walther J, Pawley AL, Sochacka NW. Exploring ethical validation as a key consideration in interpretive research quality. 2015 ASEE Annual Conference Expo
[homepage on the Internet]. 2015 [cited 27 September 2019]. Available from: https://peer.asee.org/24063

38. Creswell JW. Research design: Qualitative. Quantitative \& mixed methods approaches. 4th ed. Los Angeles, CA: Sage; 2014.

39. Howard GR. We can't teach what we don't know. White teachers, multiracial schools. New York, NY: Columbia University, Teachers College Press, 2006; p. 78-82.

40. Steyn M, McEwen H, Tsekwa J. Hyperracialized: Interracial relationships in postapartheid South Africa and the informal policing of public spaces. Ethn Racia Stud. 2018;0(0):1-17.

41. Baumeister RF. Self-control, ego depletion, and social psychology's replication crisis. In: Mele A, editor. Surrounding self-control. New York, NY: Oxford, 2018, p. 1-13.

42. Reygan F, Steyn M. Diversity in basic education in South Africa: Intersectionality and critical diversity literacy. Africa Educ Rev. 2017;14(2):68-81. https://doi.org/ 10.1080/18146627.2017.1280374

43. Wassermann J. Teaching controversial issues in History. In: Van Eeden ES, Warnich P, editors. Teaching and learning history and geography in the South African classroom. 1st ed. Pretoria: Van Schaik Publishers, 2018; p. 113-131. 